\title{
DETERMINING THE NECESSITY OF COMPLEMENTARY AXILLARY DISSECTION IN BREAST CANCER PATIENTS WITH POSITIVE SENTINEL LYMPH NODE BY WAY OF ASSESSING NOMOGRAM METHODS
}

\section{POZİTIF SENTİNEL LENF DÜĞÜMÜ OLAN MEME KANSERLİ HASTALARDA TAMAMLAYICI AKSİLLER DİSEKSIYON GEREKLİLİĞINİN NOMOGRAM YÖNTEMLERİNIN DEĞERLENDİRILMESIYYLE BELIRLENMESİ}

Dursun Burak OZDEMIR ${ }^{1}$, Betul BOZKURT ${ }^{2}$

\begin{abstract}
AIM: Our aim was to evaluate the efficacies of different nomogram approaches, including the Memorial Sloan Kettering Cancer Centre (MSKCC), Stanford University, Tenon Hospital, Cambridge University and TR methods, in patients operated for breast cancer.

MATERIAL AND METHOD: The study included 60 breast cancer patients who were operated on for breast cancer at Ankara Numune Training and Research Hospital, A2 General Surgery Clinic, between 2007 and 2012. All patients were sentinel lymph node (SLN)-positive and had undergone axillary lymph node dissection (ALND). Five different scoring systems were applied retrospectively to these 60 patients. Receiver operating characteristics (ROC) curves were created for the nomograms and the area under the curve (AUC) sensitivity and specificity results were calculated.
\end{abstract}

RESULTS: Twenty-two patients (37\%) had axillary non-SLN metastases. AUC values of MSKCC, Stanford, Cambridge, Tenon and TR nomogram were calculated as $0.646,0.644,0.62,0.595$, and 0.66 , respectively. A significant difference was found between the groups with and without non-SLN metastasis in terms of SLN metastasis size $(\mathrm{p}=0.013)$

CONCLUSION: The MSKCC, Stanford, Cambridge, Tenon, and TR nomogram models were found to have insufficient power to discriminate between patients with and without non-SLN metastases in patients with SLN-positive breast cancer (AUC values $<0.70$ ).

Keywords: Breast cancer, Sentinel lymph node, Non-sentinel lymph node, Nomogram

\section{ÖZET}

AMAÇ: Amacımız meme kanseri nedeniyle ameliyat edilen hastalarda farklı nomogram yaklașimları olan Memorial Sloan Kettering Kanser Merkezi (MSKCC), Stanford Üniversitesi, Tenon Hastanesi, Cambridge Üniversitesi ve TR yöntemlerininin etkinliklerini değerlendirmekti.

GEREÇ VE YÖNTEM: Araştırmaya Ankara Numune Eğitim ve Araştırma Hastanesi A2 Genel Cerrahi Kliniği'nde 2007-2012 yilları arasında meme kanseri nedeniyle ameliyat olan 60 meme kanserli hasta dahil edildi. Tüm hastalar sentinel lenf nodu (SLN) pozitifti ve aksiller lenf nodu diseksiyonu (ALND) geçirmiști. Bu 60 hastaya retrospektif olarak beş farklı skorlama sistemi uygulandı. Nomogramlar için receiver operating characteristics (ROC) eğrileri oluşturulmuş ve eğri altında kalan alan (AUC), duyarlılık ve özgüllük sonuçları hesaplanmıştır.

BULGULAR: Yirmi iki hastada (\%37) aksiller SLN dışı metastaz vard. MSKCC, Stanford, Cambridge, Tenon ve TR nomogramlarının AUC değerleri sirasiyla $0.646,0.644,0.62,0.595$ ve 0.660 olarak hesaplandı. SLN metastazı boyutu acisindan SLN metastazı olan ve olmayan gruplar arasinda anlamlı fark bulundu $(\mathrm{p}=0.013)$.

SONUÇ: MSKCC, Stanford, Cambridge, Tenon ve TR nomogram modellerinin, SLN pozitif meme kanserli hastalarda SLN diș1 metastazları olan ve olmayan hastaları ayırt etmek için yetersiz güce sahip olduğu bulundu (AUC değerleri $<0,70$ ). Ancak TR nomogramının en yüksek özgüllüğe sahip olduğu saptandı.

Anahtar Kelimeler: Meme kanseri, Sentinel lenf nodu, Sentinel olmayan lenf nodu, Nomogram

\footnotetext{
${ }^{1}$ Department of Surgical Oncology, Eskisehir Osmangazi University Faculty of Medicine, Eskisehir, Turkey

${ }^{2}$ General Surgery, Private Office, Ankara, Turkey
}

Geliş Tarihi / Submitted : Ekim 2021 / Ekim 2021

Kabul Tarihi / Accepted : Kasım 2021 / November 2021

\footnotetext{
Sorumlu Yazar / Corresponding Author:

Dursun Burak OZDEMIR

Department of Surgical Oncology, Eskisehir Osmangazi University Faculty of Medicine, ESOGU

Meselik Kampusu Buyukdere Prof. Dr. Nabi Avci Bulvari No:4 26040 Eskisehir, Turkey

Gsm: +905334310682

E-mail: dursun_burak@yahoo.com
}

Yazar Bilgileri /Author Information:

Dursun Burak OZDEMIR (ORCID: 0000-0002-3672-5738),

Betul BOZKURT (ORCID: 0000-0003-1115-9538)

E-mail: b2bozkurt@yahoo.com

The study was approved by the Scientific Research Evaluation Commission of Ankara Numune Training and Research Hospital (No: 2012-457, Date: 10/10/2012). 


\section{INTRODUCTION}

According to GLOBOCAN data, which examines 36 cancer types in 185 countries, female breast cancer is the most frequently diagnosed cancer in the year 2020, surpassing lung cancer (1). While 2,261,419 (11.7\%) new female breast cancer cases were reported in 2020 , breast cancer was the 5th leading cause of cancer-related death $(6.9 \%)(684,996)$ among all cancer types (1). The survival time in breast cancer is increasing due to cancer screening, early diagnostic methods, and advances in treatment approaches and medical technology (2).

Over time, the surgical approach to breast cancer has evolved from radical mastectomy to modified radical mastectomy, and then to breast-conserving surgery (3). Knowing the status of the axilla in breast cancer is critical for staging, adjuvant treatment planning, survival and disease-free survival. The presence and number of metastatic lymph nodes in the axilla are the most important prognostic factors $(4,5)$. In the presence of axillary lymph node involvement, axillary lymph node dissection (ALND) or sentinel lymph node (SLN) biopsy (SLNB) can be used.

ALND has been used for a long time for axillary assessment in the past. The advantages of ALND are that it helps in staging the disease, making a more accurate prognosis estimation, providing local control in the axilla, deciding on adjuvant systemic therapy and possible contribution to survival (6). However, ALND is the most important cause of morbidity associated with breast cancer surgery, as it can cause complications such as oedema, seroma, injury of vessels and nerves in the axilla, pain in the arm, limitation of movement, numbness and tingling sensation (7). When the historical development of breast cancer surgery is examined, ALND has been performed in cases with metastasis as determined by SLNB in classical practices (8). Especially in the light of the ACOSOGZ11 study and subsequent studies, it was revealed that performing ALND in SLNB-positive patients did not have an effect on local recurrence and survival, and a less aggressive approach was dominant in the surgical management of the axilla (8).

SLNB allows avoidance of the complications of axillary dissection to some extent. When the clinical applications of the American Society of Oncology (ASCO) and National Comprehensive Cancer Network (NCCN) guidelines are reviewed, it is recommended to perform SLNB in patients with negative axilla, to avoid ALND in SLNB-negative patients, and to perform ALND in SLNBpositive patients (8). These data provided the basis for increased use of SLNB, and prevented the application of ALND in patients without clinically palpable lymph nodes in the axilla. However, metastasis is not detected in nonSLN sites in $30-70 \%$ of ALNDs performed in patients with SLNB metastasis (9). In this case, it becomes important to be able to determine non-SLN positivity with noninvasive methods. For this purpose, nomograms used to predict non-SLN status have been developed.
Nomograms aim to predict non-SLN metastasis in patients with SLN-positive breast cancer and to prevent possibly unnecessary ALND, thus avoiding complications that may occur due to ALND. The distinctive abilities of these various models differ between different populations. Therefore, it is crucial to validate these tools before applying the results to a specific population. We evaluated the effectiveness of the Memorial Sloan Kettering Cancer Centre (MSKCC), Cambridge, Stanford, Tenon score and the nomogram (TR nomogram) developed by Gür et al. in our patient population. The aim of this study was to determine the rate of unnecessary complementary axillary dissection performed in breast cancer patients with SLN positivity in our clinic, and to investigate whether this can be prevented with current nomogram methods.

\section{MATERIAL AND METHOD}

The clinical data of 60 patients who were operated for breast cancer at Ankara Numune Training and Research Hospital A2 General Surgery Clinic between 2007 and 2012 and who were found to be SLN-positive and underwent ALND were evaluated. During SLNB, only blue dye was used in 30 patients, only lymphoscintigraphy and gamma probe in 24 patients, and blue dye, lymphoscintigraphy and gamma probe were used together in 6 patients. The patients' age, localization of the primary tumour, clinical and pathological size, type, grade, presence of DCIS necrosis in the primary tumour, presence of lymphovascular invasion, presence of multifocality, oestrogen, progesterone and cerbB-2 receptor status, the number of excisions performed for the primary tumour, the current surgical margin after excision, the number of tumour positive and negative SLNs, whether the SLN metastasis was micro or macro metastasis, the metastatic SLN extracapsular spread status, whether frozen section was used for SLN examination, the size of SLN metastasis and the detection method of SLN metastasis were recorded from the automation system and clinical breast cancer follow-up forms. The MSKCC and Stanford nomograms were calculated with the help of an online calculator $(10,11)$. Tenon score, Cambridge nomogram and the TR nomogram developed by Gür et al. in 2009 were calculated manually (12-14).

\section{Ethical Approval}

All procedures performed in studies involving human participants were in accordance with the ethical standards of the institutional and/or national research committee and with the 1964 Helsinki Declaration and its later amendments or comparable ethical standards. The study was approved by the Scientific Research Evaluation Commission of Ankara Numune Training and Research Hospital (No: 2012-457, Date: 10/10/2012). Informed consent was obtained from all individual participants included in the study.

\section{Statistical Analysis}

Statistical analyses were performed in SPSS for Windows Version 15.0 package program. Numerical variables were summarized as mean \pm standard deviation and median [min-max] values, and qualitative variables were 
summarized as numbers and percentages. Shapiro-Wilk's test was used to investigate whether the numerical data showed a normal distribution. In addition to descriptive statistical methods [mean, standard deviation and median $(\min -\max )]$ in the evaluation of data, the Student's t-test or the Mann-Whitney U test were used for comparison of groups, and Chi-Square tests were used for the comparison of qualitative data. Variables predicting NSLN metastasis were determined by logistic regression analysis. The power of MSKCC, Cambridge, Stanford nomograms, Tenon score and the nomogram developed by Gür et al. to detect the presence of non-SLN metastasis was determined by ROC curve analysis. The area under curve (AUC) was found for each test. The cut-off points of the tests and their sensitivity (based on the identification of those with non-SLN metastases) and the specificity (based on the identification of those without non-SLN metastases) were calculated. Significance level was taken as $\mathrm{p}<0.05$.

\section{RESULTS}

The age distribution of the patients ranged from 37 to 78 years. Thirteen patients were clinically stage I ( $22 \%)$, 33 patients were stage IIA (55\%), and 14 patients were stage IIB (23\%). All stage IIB patients were T3N0M0. The mean age of the study group was $54.3 \pm 10.9$ years. Of the 60 SLN-positive patients, 22 (37\%) had non-SLN metastases, and 38 (63\%) had no non-SLN metastases. Non-SLN metastasis rates were $15 \%$ in stage I patients, $38 \%$ in stage IIA patients, and $35 \%$ in stage IIB patients.

A significant difference was found between the groups with and without non-SLN metastasis in terms of MSKCC and TR nomogram values $(\mathrm{p}=0.047$ and $\mathrm{p}=0.040$, respectively); however, there was no significant difference in terms of Stanford and Cambridge nomogram values and Tenon scores $(\mathrm{p}=0.065, \mathrm{p}=0.170$ and $\mathrm{p}=0.117$ respectively). The mean MSKCC and TR nomogram values were found to be higher in the group with non-SLN metastases (Table 1).

There was no significant difference between the groups with and without non-SLN metastasis in terms of pathological tumour size and form of SLN metastasis (micro metastasis/macro metastasis). There was no significant result reached in terms of the form of SLN metastasis between the groups with and without non-SLN metastasis $(p=0.077)$. A significant difference was found between the groups with and without non-SLN metastasis in terms of SLN metastasis size $(\mathrm{p}=0.013)$ (Table 2).

Although there was a significant difference between the groups with and without non-SLN metastasis in terms of SLN metastasis size, it was found that SLN metastasis size was not an independent predictive factor for nonSLN metastasis. The predictive value of SLN metastasis size in terms of non-SLN metastasis was found to have a $\mathrm{p}$ value of 0.128 . Odds ratio (95\% Confidence interval) was found to be 1.07 (95\% CI: 0.98-1.17).

The optimal cut-off point was 51.5 in the MSKCC nomogram, 30.85 in the Stanford nomogram, 0.38 in the Cambridge nomogram, 0.41 in the TR nomogram, and 5.25 in the Tenon score. Among these five parameters, the TR nomogram was found to be the nomogram that had the highest power to distinguish between patients with and without metastases. However, none of the nomogram methods demonstrated remarkable diagnostic value. Nonetheless, it was found that the Stanford nomogram had the highest sensitivity and the TR nomogram had the highest selectivity (Table 3) (Figure 1).

Table 1. Distribution of MSKCC, Cambridge, Stanford nomograms, Tenon score, and TR nomogram between groups with and without non-SLN metastases.

\begin{tabular}{|c|c|c|c|c|}
\hline & $\underset{(n=60)}{\text { All patients }}$ & $\begin{array}{c}\text { No nonsentinal } \\
\text { metastases }(n=38)\end{array}$ & $\underset{(n=22)}{\operatorname{nonsentinal~metastasis}}$ & $\mathbf{p}$ \\
\hline $\operatorname{MSKCC}($ Mean $\pm S D)$ & $48,0 \pm 18,2$ & $44,5 \pm 16,3$ & $54,1 \pm 20,0$ & $0,047^{\star}$ \\
\hline $\begin{array}{l}\text { Stanford }(\text { Mean } \pm \text { SD) } \\
\text { Median }[\min -\max ]\end{array}$ & $\begin{array}{c}62,0 \pm 30,9 \\
64,5[6,5-100]\end{array}$ & $\begin{array}{c}56,7 \pm 32,0 \\
56,7[6,5-100]\end{array}$ & $\begin{array}{c}71,3 \pm 27,3 \\
79[17-100]\end{array}$ & 0,065 \\
\hline $\begin{array}{l}\text { Tenon score }(\text { Mean } \pm \text { SD }) \\
\text { Median }[\min -\max ]\end{array}$ & $\begin{array}{c}5,2 \pm 1,6 \\
5,5[1-7]\end{array}$ & $\begin{array}{c}4,9 \pm 1,8 \\
5,3[1-7]\end{array}$ & $\begin{array}{c}5,7 \pm 1,1 \\
6[3,5-7]\end{array}$ & 0,117 \\
\hline $\begin{array}{l}\text { TR }(\text { Mean } \pm \text { SD }) \\
\text { Median [min - max] }\end{array}$ & $\begin{array}{c}0,22 \pm 0,20 \\
0,12[0,04-0,89]\end{array}$ & $\begin{array}{c}0,18 \pm 0,15 \\
0,11[0,04-0,57]\end{array}$ & $\begin{array}{c}0,30 \pm 0,24 \\
0,15[0,06-0,89]\end{array}$ & $0,040^{*}$ \\
\hline Cambridge (Mean \pm SD) & $0,41 \pm 0,23$ & $0,37 \pm 0,22$ & $0,46 \pm 0,25$ & 0,170 \\
\hline
\end{tabular}

Table 2. Distribution of pathologic tumour size, SLN metastasis form and SLN metastasis size between groups with and without non-SLN metastases.

\begin{tabular}{l|c|c|c|c|} 
& $\begin{array}{c}\text { All patients } \\
(\mathbf{n = 6 0 )}\end{array}$ & $\begin{array}{c}\text { non-SLN metastases } \\
\text { absent }(\mathbf{n}=\mathbf{3 8})\end{array}$ & $\begin{array}{c}\text { non-SLN metastasis } \\
\text { present }(\mathbf{n}=\mathbf{2 2})\end{array}$ & p \\
\hline Pathologic tumour size (Mean \pm SD) & $2,6 \pm 1,3$ & $2,5 \pm 1,4$ & $2,8 \pm 1,3$ & 0,329 \\
\hline Median [min - max] & $2,5[0,6-7,0]$ & $2,4[0,6-7,0]$ & $2,5[1,0-6,0]$ & \\
\hline SLN metastasis form (Macro/Micro) & $54 / 6$ & $32 / 6$ & $22 / 0$ & 0,077 \\
\hline SLN metastasis size (mm) (Mean \pm SD) & $8,57 \pm 6,0,78$ & $(\% 84,2 / \% 15,8)$ & $(\% 100 / \% 0)$ & \\
Median [min - max] & $7[1-30]$ & $7,26 \pm 6,57$ & $10,82 \pm 6,67$ & $0,013^{*}$ \\
\hline
\end{tabular}




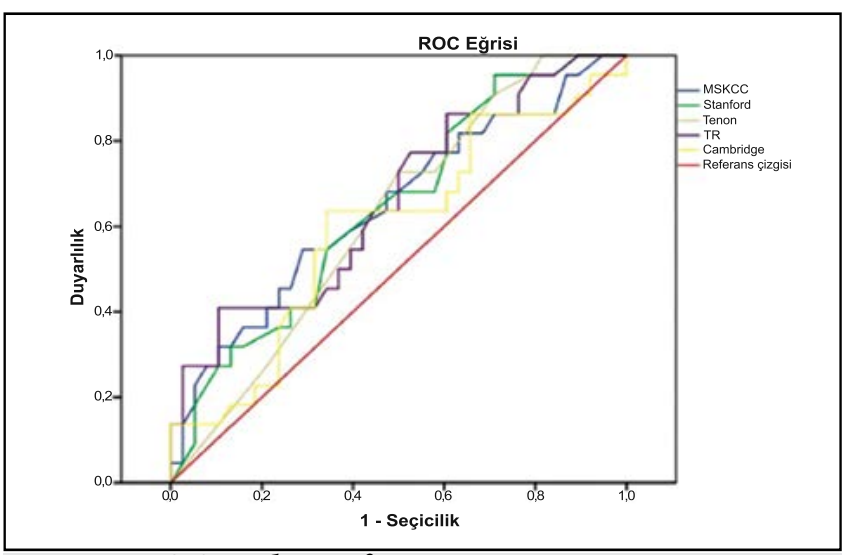

Figure 1. ROC analysis of nomograms.

\section{DISCUSSION}

In order to avoid unnecessary axillary lymph node dissection in patients with early-stage breast cancer without axillary involvement, SLNB has been used in many surgical clinics in recent years because it has less morbidity compared to ALND and can provide prognostic information. Prior studies have established that the morbidity of SLNB is much lower than ALND, and that SLNB is a very good indicator of axilla status $(15,16)$.

After several pioneering studies concluded that axillary lymph node dissection did not provide significant prognostic benefit to patients, studies seeking ways to protect the axilla continued, ultimately leading to development of nomograms to predict nonSLN metastasis in SLN-positive patients $(17,18)$. The nomogram and scoring systems aim to identify patients with SLN involvement and without non-SLN involvement, in order to reduce unnecessary application of complementary ALND. This approach has been shown to help improve the quality of life of patients $(12,13,19,20)$. When the condition before and after the nomograms is evaluated, it was observed that the rates of ALND application in SLN-positive patients were significantly lower in the post-nomogram period (21). Only $35 \%$ to $50 \%$ of SLN-positive breast cancer patients have non-SLN involvement (22). In our study, this rate was calculated as $37 \%$, similar to the rates in the literature.

The first study of nomograms was done by Van Zee et al. from MSKCC in 2003 (19). In this retrospective study, the AUC value for the MSKCC nomogram was reported to be 0.76 . Later, MSKCC tested this nomogram in 373 patients with a prospective study, and in this study, the AUC value was found to be 0.77 , and therefore, the authors argued that this nomogram method was practical and reliable (23). Although the pathology-based MSKCC nomogram is used in many centres to determine a patient's risk for non-SLN metastases, its accuracy varies between populations (AUC values range from 0.58 to 0.86$)(24,25)$. Degnim et al. reported that the MSKCC nomogram had a 0.86 AUC value and had a strong discriminatory ability (24). However, Klar et al. reported the AUC value of MSKCC nomogram as 0.58 in their study (25). Again, in 2006, Smidt et al. applied the MSKCC nomogram to 222 SLN-positive breast cancer patients who underwent ALND in a centre in the Netherlands and found the AUC value to be 0.77 (26). In our study, the AUC value of the MSKCC nomogram was determined as 0.646 , the sensitivity of the nomogram was $55 \%$, the selectivity was $71 \%$, and the cut-off value was calculated as 51.5 . In our study, it was determined that the MSKCC nomogram was moderately valuable, that it was somewhat predictive method-albeit with insufficient statistical discriminatory power in clinical applications, and it was concluded that it was not suitable for our patient population. Significant differences between studies in various populations may be related to detection methods and pathological evaluation criteria of SLN.

In the Tenon model defined by Barranger et al. in 2005, SLN metastasis size was reported as the strongest predictive factor predicting non-SLN involvement (12). In our study, a significant difference was found between the groups with and without non-SLN metastasis in terms of SLN metastasis size, but it was found that SLN metastasis size was not an independent predictive factor for non-SLN metastasis. Many studies have been conducted to evaluate the accuracy of the Tenon scoring system. In these studies, AUC values ranged from 0.58 to 0.7 (27). In our study, the AUC value of the Tenon scoring system was calculated as 0.62 , the sensitivity as $72.7 \%$, the selectivity as $50 \%$, and the cut-off value was 5.25. In our study, it was determined that the tenon scoring system was moderately significant, and that it was a predictive method with insufficient statistical discriminatory power in clinical applications.

In the Cambridge model defined by Pal et al.in 2008, many parameters were examined and a formula containing 3 predictive factors was developed (13). Primary tumour grade, SLN metastasis diameter, number of metastatic SLNs/total number of SLNs excised were taken into account. They calculated the MSKCC nomogram and the Cambridge nomogram they developed to predict

Table 3. Criteria for the diagnostic value of nomograms.

\begin{tabular}{|c|c|c|c|c|c|}
\hline & AUC & p & Cut-off & Sensitivity & Selectivity \\
\hline MSKCC nomogram & $\% 64,6$ & 0,061 & 51,5 & $\% 54,5$ & $\% 71,1$ \\
\hline Stanford nomogram & $\% 64,4$ & 0,066 & 30,85 & $\% 95,5$ & $\% 28,9$ \\
\hline Tenon scor & $\% 62$ & 0,123 & 5,25 & $\% 72,7$ & $\% 50$ \\
\hline TR nomogram & $\% 66$ & 0,040 & 0,41 & $\% 41$ & $\% 90$ \\
\hline Cambridge nomogram & $\% 59,5$ & 0,223 & 0,38 & $\% 64$ & $\% 66$ \\
\hline
\end{tabular}


non-SLN metastasis in 118 patients. The MSKCC nomogram AUC value was calculated as 0.68 , and the Cambridge nomogram AUC value was 0.84. As a result, the Cambridge nomogram was reported to be more effective in predicting non-SLN metastasis. In our study, an inverse result was found. The MSKCC nomogram AUC value was 0.646 , while the Cambridge nomogram AUC value was 0.595 . In our study, it was determined that the Cambridge nomogram was also somewhat predictive, but had insufficient statistical discrimination power in clinical applications.

In 2008, Kohrt et al. applied the MSKCC nomogram in their patient population at Stanford University School of Medicine and reported the AUC value as 0.62 . They concluded that the MSKCC nomogram was not suitable for their population and published their own nomogram, the Stanford nomogram, with an AUC value of 0.74 (20). In a multicentre prospective study, 285 of 784 breast cancer patients were found to be SLN-positive and the variables found to be significant with ALND results were analysed by regression analysis. According to this model, the probability of non-SLN metastasis in patients with isolated tumour cells as a result of SLNB was 4.7\%, the probability of non-SLN metastasis in patients with micro metastasis was $42 \%$, and the probability of nonSLN metastasis in patients with macro metastasis was $71 \%$. In our study, the relationship between SLN micro metastasis/macro metastasis and non-SLN metastasis was investigated. Although none of the 6 patients with SLN micro metastases had non-SLN metastases (0\%), a significant result could not be reached due to the small number of patients with micro metastases $(p=0.077)$. In our study, the rate of non-SLN metastasis was found to be $41 \%$ in patients with SLN macro metastasis, and the Stanford nomogram AUC value was calculated as 0.644, while sensitivity was $95.5 \%$ and specificity was $28.9 \%$ with a cut-off value of 30.8 . In our study, the Stanford model was the method with the highest sensitivity, but it was found to be a moderately significant predictive method with insufficient statistical discriminatory power in clinical applications.

In 2008, Gür et al. retrospectively calculated the MSKCC, Stanford, Cambridge nomograms and Tenon score of 319 SLN-positive breast cancer patients who underwent ALND and they reported the AUC values of $0.70,0.64,0.69$, and 0.69 , respectively. They reported the best predictive method as the MSKCC nomogram (28). In 2009, Gür et al. calculated the MSKCC, Cambridge, Stanford nomograms and Tenon score of 607 breast cancer patients who underwent ALND in Turkey, and reported AUC values of $0.70,0.71,0.73$, and 0.53 , respectively. In the same study, they reported a nomogram with their own formulation, which had an AUC value of $80 \%$ in these patients (14). In our study, the AUC value of this nomogram was calculated as $66 \%$, while sensitivity was $41 \%$ and specificity was $90 \%$ with a cut-off value of 0.41 . Although it was the method with the highest AUC value and specificity in our study, it was also found to be a moderately significant predictive method -similar to the other nomogram methods.

Predictors of metastatic non-SLN are primarily the features of the primary tumour and features of the metastatic SLN. Strong independent predictive factors for non-SLN metastases were reported to be primary tumour diameter and diameter of SLN metastases by Reynolds and colleagues (29). Non-SLN metastasis rates predicted in the literature according to tumour diameter are between 0-50\% for T1 tumours, $20-50 \%$ for T2 tumours, and $50-80 \%$ for T3 tumours (30). In our study, these rates were calculated as $20 \%, 46 \%$, and $40 \%$, respectively, indicating similarities with the literature. In our study, no significant relationship was found between primary tumour size and non-SLN metastasis $(p=0.329)$. In addition, although a significant difference was found in terms of SLN metastasis size between the groups with and without non-SLN metastasis in our study ( $p=0.013)$, SLN metastasis size was also not an independent predictive factor for non-SLN metastasis $(\mathrm{p}=0.128)$. While the Cambridge and TR nomogram formulation was being created, SLN metastasis size was found to be associated with non-SLN metastasis size and was included in the formula $(13,14)$. This relationship has been confirmed in many publications, and it is seen that local tumour burden has an effect on the development of axillary lymph node metastases (31-33).

Currently, there are no instruments other than the nomograms and scoring systems for the evaluation of non-SLN metastasis in breast cancer patients with SLN metastasis. The performances of these nomogram and scoring systems givethemost reliable and appropriate results in the centres where they were developed. The reasons for this are most likely patient inclusion criteria, biases in sample selection, and inherent flaws in retrospective and cross-sectional studies. In addition, the accuracy of different nomograms varies in different centres as it becomes very difficult to ensure data specificity and integrity as a result of the problems arising from imaging processing and the differences in data entry for pathological and histological laboratory results. The narrow patient population selected during the development of nomogram and scoring systems is another factor limiting the general use of nomogram and scoring systems. The purpose of nomogram and scoring systems is not direct decision-making, but to guide them in assessing risks and assist in joint decision making with the patient for better treatment. Therefore, nomograms and scoring systems need evaluation and validation of their use in multiple centres.

\section{CONCLUSION}

In our study, it has been shown that currently available nomograms do not have sufficient value for definite predictive use. The most valuable nomogram in our study is not the MSKCC nomogram, which is the most accepted model today, but the nomogram developed by Gür and colleagues. This may be because this nomogram was developed with the Turkish patient population. In studies to be conducted with more patients, the utility of the TR 
nomogram developed by Gür et al. must be assessed. In conclusion, there is a need for further development of existing nomograms in order to evaluate the possibility of accurately detecting non-SLN metastasis in patients with SLN-positive breast cancer and plan treatment accordingly. Also, seeking other parameters that could support nomogram outcomes may be necessary.

Conflict of Interest: No potential conflict of interest was reported by the authors.

\section{Author Contributions}

DBO: Data analysis and interpretation, drafting the article, final approval of the version to be published.

BB: Substantial contributions to conception and design of the study and the article.

Sponsor's Role:This research received no specific grant from any funding agency

\section{REFERENCES}

1) Sung H, Ferlay J, Siegel RL, et al. Global Cancer Statistics 2020: GLOBOCAN Estimates of Incidence and Mortality Worldwide for 36 Cancers in 185 Countries. CA Cancer J Clin. 2021; 71: 209-49.

2) Özbalcı GS, Özbalcı AB, Tuncal S. Meme koruyucu cerrahi sonrası lokal nüks. Ankara Eğitim ve Araştırma Hastanesi Tıp Dergisi. 2016; 49: 46-54.

3) Ozkazanc Kulduk G. Meme Koruyucu Cerrahi Ve Sentinel Lenf Nodu Biyopsi Materyallerinin İntraoperatif Patolojik Değerlendirilmesi. In: Gül VO, Şahin M, Babayiğit M, et al., editors. Peroperatif Hasta Yöntemi. Ankara: Berikan Yayınevi; 2021. p. 141-8. 4) Anderson BO, Austin-Seymour MM, Gralow JR, et al. A Multidisciplinary Approach to Locoregional Management of the Axilla for Primary Operable Breast Cancer. Cancer Control. 1997; 4: 491-9.

5) Weaver DL, Krag DN, Ashikaga T, et al. Pathologic analysis of sentinel and nonsentinel lymph nodes in breast carcinoma: a multicenter study. Cancer. 2000; 88: 1099-107.

6) Schrenk P, Rieger R, Shamiyeh A, et al. Morbidity following sentinel lymph node biopsy versus axillary lymph node dissection for patients with breast carcinoma. Cancer. 2000; 88: 608-14.

7) Valero MG, Muhsen S, Moo TA, et al. Increase in Utilization of NippleSparing Mastectomy for Breast Cancer: Indications, Complications, and Oncologic Outcomes. Ann Surg Oncol. 2020; 27: 344-51.

8) Giuliano AE, McCall L, Beitsch P, et al. Locoregional recurrence after sentinel lymph node dissection with or without axillary dissection in patients with sentinel lymph node metastases: the American College of Surgeons Oncology Group Z0011 randomized trial. Ann Surg. 2010; 252: 426-32; discussion 32-3.

9) Veronesi U, Paganelli G, Viale G, et al. A randomized comparison of sentinel-node biopsy with routine axillary dissection in breast cancer. N Engl J Med. 2003; 349: 546-53.

10) Center MSKC. Breast Cancer Nomogram: Breast Additional Non SLN Metastases. 2021; Available at: http://nomograms.mskcc. org/Breast/BreastAdditionalNonSLNMetastasesPage.aspx. Access date: 20.03.2021.

11) tools P. 2021; Available at: http://www3-hrpdcc.stanford.edu/ nsln-calculator.

12) Barranger E, Coutant $C$, Flahault $A$, et al. An axilla scoring system to predict non-sentinel lymph node status in breast cancer patients with sentinel lymph node involvement. Breast Cancer Res Treat. 2005; 91: 113-9.

13) Pal A, Provenzano E, Duffy SW, et al. A model for predicting non-sentinel lymph node metastatic disease when the sentinel lymph node is positive. Br J Surg. 2008; 95: 302-9.

14) Gur AS, Unal B, Ozbek U, et al. Validation of breast cancer nomograms for predicting the non-sentinel lymph node metastases after a positive sentinel lymph node biopsy in a multi-center study. Eur J Surg Oncol. 2010; 36: 30-5.

15) Galimberti V, Cole BF, Viale G, et al. Axillary dissection versus no axillary dissection in patients with breast cancer and sentinel-node micrometastases (IBCSG 23-01): 10-year follow-up of a randomised, controlled phase 3 trial. Lancet Oncol. 2018; 19: 1385-93.

16) Sávolt Á, Péley G, Polgár C, et al. Eight-year follow up result of the OTOASOR trial: The Optimal Treatment Of the Axilla Surgery Or Radiotherapy after positive sentinel lymph node biopsy in early-stage breast cancer: A randomized, single centre, phase III, non-inferiority trial. Eur J Surg Oncol. 2017; 43: 672-9.

17) Fisher B, Jeong JH, Anderson S, et al. Twenty-five-year followup of a randomized trial comparing radical mastectomy, total mastectomy, and total mastectomy followed by irradiation. N Engl J Med. 2002; 347: 567-75.

18) Veronesi $U$, Marubini $E$, Mariani $L$, et al. The dissection of internal mammary nodes does not improve the survival of breast cancer patients. 30-year results of a randomised trial. Eur J Cancer. 1999; 35: 1320-5.

19) Van Zee KJ, Manasseh DM, Bevilacqua JL, et al. A nomogram for predicting the likelihood of additional nodal metastases in breast cancer patients with a positive sentinel node biopsy. Ann Surg Oncol. 2003; 10: 1140-51.

20) Kohrt HE, Olshen RA, Bermas HR, et al. New models and online calculator for predicting non-sentinel lymph node status in sentinel lymph node positive breast cancer patients. BMC Cancer. 2008; 8: 66. 21) Park J, Fey JV, Naik AM, et al. A declining rate of completion axillary dissection in sentinel lymph node-positive breast cancer patients is associated with the use of a multivariate nomogram. Ann Surg. 2007; 245: 462-8.

22) Unal B, Gur AS, Ahrendt G, et al. Can nomograms predict nonsentinel lymph node metastasis after neoadjuvant chemotherapy in sentinel lymph node-positive breast cancer patients? Clin Breast Cancer. 2009; 9: 92-5.

23) Sasada T, Murakami S, Kataoka T, et al. Memorial SloanKettering Cancer Center Nomogram to predict the risk of nonsentinel lymph node metastasis in Japanese breast cancer patients. Surg Today. 2012; 42: 245-9.

24) Degnim AC, Reynolds C, Pantvaidya G, et al. Nonsentinel node metastasis in breast cancer patients: assessment of an existing and a new predictive nomogram. Am J Surg. 2005; 190: 543-50.

25) Klar M, Foeldi M, Markert S, et al. Good prediction of the likelihood for sentinel lymph node metastasis by using the MSKCC nomogram in a German breast cancer population. Ann Surg Oncol. 2009; 16: 1136-42. 26) Smidt ML, Kuster DM, van der Wilt GJ, et al. Can the Memorial Sloan-Kettering Cancer Center nomogram predict the likelihood of nonsentinel lymph node metastases in breast cancer patients in the Netherlands? Ann Surg Oncol. 2005; 12: 1066-72.

27) Andersson Y, Frisell J, de Boniface J, et al. Prediction of nonsentinel lymph node status in breast cancer patients with sentinel lymph node metastases: evaluation of the tenon score. Breast Cancer (Auckl). 2012; 6: 31-8.

28) Gur AS, Unal B, Johnson R, et al. Predictive probability of four different breast cancer nomograms for nonsentinel axillary lymph node metastasis in positive sentinel node biopsy. J Am Coll Surg. 2009; 208: 229-35.

29) Reynolds C, Mick R, Donohue JH, et al. Sentinel lymph node biopsy with metastasis: can axillary dissection be avoided in some patients with breast cancer? J Clin Oncol. 1999; 17: 1720-6.

30) Unal B, Gur AS, Kayiran O, et al. Models for predicting nonsentinel lymph node positivity in sentinel node positive breast cancer: the importance of scoring system. Int J Clin Pract. 2008; 62: 1785-91. 31) Meretoja TJ, Leidenius MH, Heikkilä PS, et al. International 
multicenter tool to predict the risk of nonsentinel node metastases in breast cancer. J Natl Cancer Inst. 2012; 104: 1888-96.

32) Mittendorf EA, Hunt KK, Boughey JC, et al. Incorporation of sentinel lymph node metastasis size into a nomogram predicting nonsentinel lymph node involvement in breast cancer patients with a positive sentinel lymph node. Ann Surg. 2012; 255: 109-15.

33) Dingemans SA, de Rooij PD, van der Vuurst de Vries RM, et al. Validation of Six Nomograms for Predicting Non-sentinel Lymph Node Metastases in a Dutch Breast Cancer Population. Ann Surg Oncol. 2016; 23: 477-81.

Ankara Eğt. Arş. Hast. Derg. (Med. J. Ankara Tr. Res. Hosp.), 2021 ; 54(3) : 405-411

The study was approved by the Scientific Research Evaluation Commission of Ankara Numune Training and Research Hospital (No: 2012-457, Date: 10/10/2012). 